\title{
Evasão nas Licenciaturas das Universidades Federais: entre a apetência e a competência
}

\author{
Dropout in the licentiates to teaching undergraduate courses of \\ Federal Universities: between inclination and competency
}

\author{
Otacilio Antunes Santana* \\ Universidade Federal de Pernambuco
}

Resumo A evasão de alunos nos cursos superiores se tornou uma temática recorrente a partir da transição de uma educação de elite para uma educação de massas. Os objetivos deste trabalho foram: i) analisar o principal momento de evasão nos cursos de licenciatura das Universidades Federais; e ii) avaliar o discurso dos alunos no início do curso, no momento da evasão, e no final do curso para aqueles que permaneceram. O trabalho seguiu dois métodos de coleta de dados: quantitativo e qualitativo; e as análises estatísticas e compreensiva (discursiva). O momento da evasão foi marcado pela redução da potência de agir pelos alunos, principalmente na metade do percurso acadêmico.

PALAVRAS-CHAVE: Potência de agir; Entrevista compreensiva; Nuvem de palavras.

\begin{abstract}
The student dropout in higher education is a recurrent thematic from the transition of elite education to mass education. The objectives of this work were: i) to analyze the main period of dropout in the licentiates to teaching undergraduate courses of Brazilian Federal Universities; and ii) to evaluate the discourse of students in begin, in dropout moment, and in last year for students that remained in course. The work followed two methods of data sample: quantitative and qualitative; and the statistical and comprehensive analyzes (discursive). The dropout moment was highlight by reduction of power to act by students; it is especially in middle of the academic route.
\end{abstract}

KEYWORDS: Power to act; Comprehensive interview; Tag clouds. 


\section{Introdução}

A tendência de uma educação compulsória e de uma educação de massas (GOMES; MORAES, 2012), com a ampliação das vagas dos cursos de ensino superior (Reestruturação e Expansão das Universidades Federais - REUNI) e toda a complexidade em aumentar o número de concluintes nos cursos de graduação, fez emergir uma pauta paralela: a evasão (SILVA FILHO et al., 2007). Evasão aqui no sentido lato sensu do termo, de abandono informal ou desistência formal do curso sem a obtenção da certificação ou colação de grau (MONTMARQUETTE; MAHSEREDJIAN; HOULE, 2001). Para além de uma problemática estatística que é um ponto de visão pragmática das políticas educacionais e de quem interessa (eg. Organização para a Cooperação e Desenvolvimento Econômico - OCDE): formação de capital humano (BECKER, 2009), os cientistas da educação se preocupam com a questão humanista (desenvolvimento humano): Por que o aluno evadiu? (ANDRIOLA; ANDRIOLA; MOURA, 2006; BAGGI; LOPES, 2011; FELICETTI; FOSSATTI, 2014).

Se por um lado Bardagi e Hutz (2009) descreveram a evasão como o único caminho individual nos relatos de quem evadiu (decisão negativa), Woodley (2004) defende a não patologização da evasão. $\mathrm{O}$ autor trata como um caminho natural no contexto histórico individual (decisão positiva). A literatura apresentou com propriedade diversos motivos apontados pelos alunos no momento da evasão (ANDRIOLA; ANDRIOLA; MOURA, 2006; SILVA FILHO et al., 2007; BARDAGI; HUTZ, 2009; BAGGI; LOPES, 2011; TONTINI; WALTER, 2014): i) falta de uma recepção e orientação no início do curso; ii) realidade distante do imaginário pré-universitário (eg. impacto de uma educação disciplinadora no ensino médio para uma educação libertadora no ensino superior); iii) um distanciamento na relação professor-aluno; iv) não identificação com as disciplinas e expectativas não correspondidas (escolha vocacional insuficiente); v) discriminação e pouca integração social; vi) falta de perspectiva com a profissão escolhida; vii) problemas familiares (eg. distância da família, ciúmes ou conservadorismo do cônjuge, etc.); viii) problemas financeiros (eg. falta de auxílios de manutenção acadêmica); ix) baixo coeficiente de rendimento acadêmico (resultado de um ensino médio defasado); $\mathrm{x}$ ) escassez de tempo (eg. incompatibilidade com horário do trabalho); e outros.

Mas, apenas esses motivos reduziriam a potência de se conseguir a colação de grau? E os que ficaram? Talvez o ponto de partida não é avaliar somente os que evadiram, mas estabelecer um paralelo com aqueles que permaneceram e concluíram, como descreveram Restaino (2008): "avaliar os sobreviventes em um curso de graduação" ou Levy (2007): “avaliar os persistentes”. Então, a hipótese aqui seria: existe um momento em que a potência de agir se reduziria a ponto da evasão ser a alternativa. Potência de agir aqui no sentido de Espinoza (2007): "a essência em ato", “o desejo que lhe coloca em movimento" (conatus). Haveria uma conjuntura de motivos que reduziria essa potência para o evadido e aumentaria a potência para o "sobrevivente" na graduação? Analisar esse momento seria o ponto crucial para diagnosticar as evasões e propor ações sensíveis aos alunos antes de seu ingresso na universidade. 
Estudar a evasão nos cursos de formação docente (licenciatura) é importante, inicialmente devido a demanda de docentes existente, e posteriormente pela origem social dos estudantes (eg. renda familiar e índice de desenvolvimento humano), a forma de ingresso (baixas notas no Exame Nacional do Ensino Médio) (SANTANA, 2015), e sua vocação a ser mediador do processo de ensino e aprendizagem que envolve a técnica (conteúdo), a prática (aula) e a poesia (sensibilidade), na semântica aristotélica (a poíesis, a téchne e a práxis; HEIDEGER, 1976). Essa aptidão (apetência) pela profissão envolve uma potência de agir além da competência (legitimidade conferida), envolve saberes sensíveis no processo (disposição natural e espontânea que orienta uma pessoa no sentido de uma atividade), na qual elevam as potencialidades do ser de quem ensina e de quem aprende (FREIRE, 2014). Os objetivos desse trabalho foram: i) analisar o principal momento de evasão nos cursos de licenciatura das Universidades Federais; e ii) avaliar o discurso no início do curso, no momento da evasão, e no final do curso para aqueles que permaneceram. Nesse trabalho não foram consideradas as licenciaturas de universidades e faculdades privadas, e de cursos a distância, pois nessas o fator de evasão estaria relacionado fortemente a questões financeiras (primeiro caso) (número de evasão maior em anos de crise), e uma falta de comprometimento do aluno (segundo caso), conforme descrito por alguns autores (ROMANOWSKI, 2002; GATTI; BARRETTO; ANDRÉ, 2011; SANTANA, 2013; MEC/INEP/DEED, 2015; DINIZ-PEREIRA, 2015).

\section{Métodos e Análises}

O trabalho seguiu dois métodos de coleta de dados: quantitativo e qualitativo; e as análises estatísticas e compreensiva (discursiva). Os dados quantitativos por ano (e semestre) sobre evasão (número de alunos evadidos na licenciatura); número de alunos matriculados; coeficiente acadêmico de rendimento (CRA); perfil dos alunos (gênero, renda familiar, distância da residência a universidade, e, idade) no início do curso (fim do $1^{\circ}$ semestre), no semestre de maior evasão, e, no fim do curso ( $8^{\circ}$ semestre) foram disponibilizados pelas pró-reitorias acadêmicas ou de ensino de graduação das universidade federais brasileiras sobre os cursos de licenciatura vigentes presenciais, balizados com os dados do Censo da Educação Superior (MEC/INEP/DEED, 2015). O período avaliado foi de 2007 a 2014, a partir da implementação do programa de Reestruturação e Expansão das Universidades Federais (REUNI).

$\mathrm{O}$ coeficiente acadêmico de rendimento (CRA) foi o estabelecido pelas universidades federais conforme designado na equação 1 (eq. 1 ).

Equação 1 - coeficiente acadêmico de rendimento.

$$
C R A=\frac{\sum_{i} N F_{i} \cdot C R D_{i}}{\sum_{i} C R D_{i}}
$$

Em que, $\mathrm{i}$ = disciplina ou componente curricular; $\mathrm{NF}=$ nota final; e, $\mathrm{CRD}$ = número de créditos cursados. Análises estatísticas foram executadas entre os momentos: o início e o fim do curso, com o período de maior evasão para as variáveis 
CRA (teste t pareado, precedido do teste de normalidade Shapiro-Wilk), e, entre as distribuições dos perfis dos alunos (teste $\chi^{2}$ ).

Entrevistas compreensivas foram realizadas de forma aberta as quais se basearam em três perguntas para os três grupos amostrais: i) para os alunos no início do curso (O que motiva você a iniciar o curso de licenciatura?); ii) para os alunos após evasão (Por que você evadiu do curso?); e iii) para os alunos no final do curso (O que lhes motiva a estarem no final do curso?). A partir das respostas foram retiradas démarches (BILLOUET, 2007) na qual permitiram a construção das narrativas balizadas pelos dados quantitativos e pela qualificação das palavras mais citadas nos dérmaches. Então, se saiu de uma questão linguística para uma questão de interpretação qualitativa (FREIRE, 1996; KAUFMANN, 2004). Para essa sistematização foi utilizada nuvem de palavras (Tag clouds) com os 100 termos de indexação mais citados, com o auxílio do aplicativo WordleTM (LEGINUS et al., 2012), para os três momentos analisados: início e fim do curso, e no momento de maior evasão. Os estudantes entrevistados foram captados por meios de sistemas de gerenciamento institucional e por redes sociais das próprias instituições. As entrevistas foram realizadas de setembro de 2007 a setembro de 2015, registradas pessoalmente com o entrevistado ou pelo aplicativo Skype (2015). Uma pesquisa fechada, escala Likert de concordância (LIKERT, 1932) foi realizada para se observar se há uma distância na concordância (SANTANA, 2014) entre os que evadiram para os que permaneceram frente as principais causas apontadas pela literatura para evasão: i) falta de uma recepção e orientação no início do curso; ii) realidade distante do imaginário pré-universitário; iii) um distanciamento na relação professor-aluno; iv) não identificação com as disciplinas e expectativas não correspondidas; v) discriminação e pouca integração social; vi) falta de perspectiva com a profissão escolhida; vii) problemas familiares; viii) problemas financeiros; ix) baixo coeficiente de rendimento acadêmico; $\mathrm{e}, \mathrm{x}$ ) escassez de tempo. Termo de Consentimento Livre e Esclarecido foram coletados anteriormente as entrevistas.

\section{Resultados e Discussão}

Todas universidades federais disponibilizaram os dados em um total de 2.252.138 matriculados e 1.358.921 de evadidos no período de 2007 a 2014 (Figura 1), com um acréscimo de $60 \%$ do número de alunos matriculados e $56 \%$ dos evadidos entre 2007 e 2014. Sem uma tendência nítida para o período, visto a relação entre o número de evadidos e matriculados, pôde-se afirmar que houve uma redução da taxa de evasão em 4\% entre 2007 e 2014, em que em alguns anos como 2008 e 2011, a evasão representou abaixo dos $55 \%$ dos alunos matriculados. Essa redução foi uma das metas da criação do REUNI (2015). 
Figura 1 - Número de alunos matriculados e evadidos, de 2007 a 2014, nos cursos de licenciatura das Universidades Federais. Relação entre evadidos e matriculados apresentados no gráfico menor.

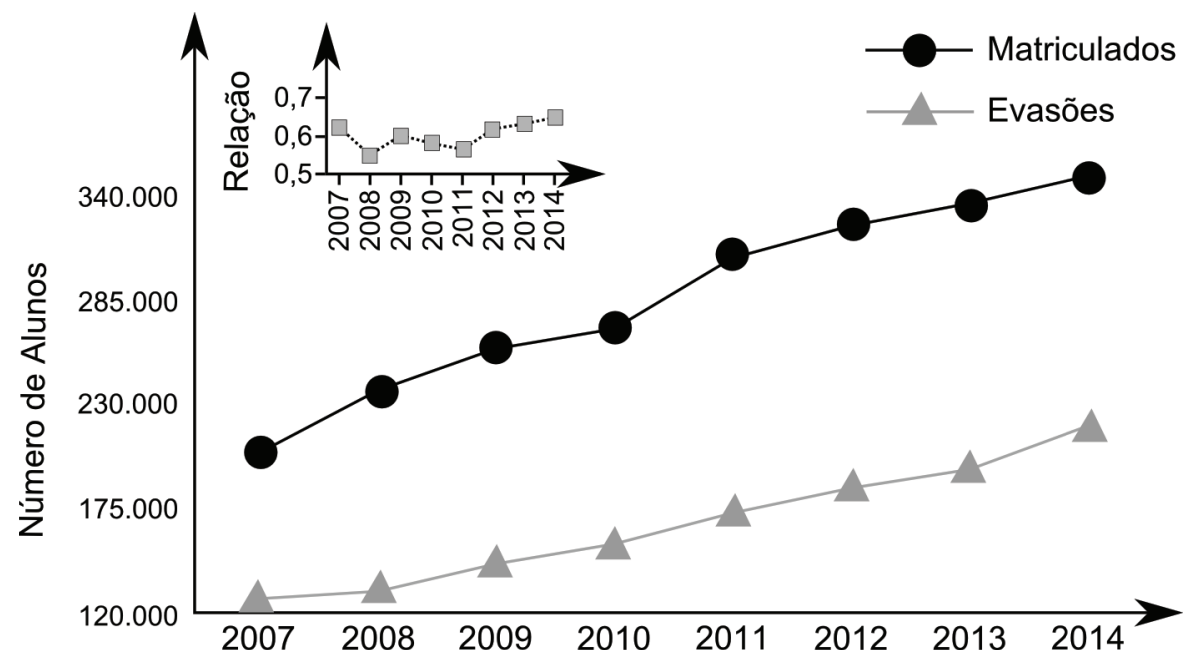

O momento de maior evasão foram justamente os anos (e semestres) que marcaram a metade do curso (final do 2 ano e início do 3 ano de licenciatura: quarto e quinto semestre) (Figura 1A), momento em que se reduziu o número de matriculados pela metade (50\%) (Figura 1B). Alguns autores descreveram que no ingresso na universidade, os alunos perpassavam pelo ciclo básico das disciplinas (do $1^{\circ}$ ao $3^{\circ}$ semestre), mesmo com repetências, para depois decidirem pela evasão ou pela persistência no curso (LEVY, 2007; GRAU-VALLDOSERA; MINGUILLÓN, 2014). 
Figura 2 - (A) Momento de maior evasão dos cursos de licenciatura $(\mathrm{n}=1.358 .921)$ e $(\mathrm{B})$ números de matriculados $(\mathrm{n}=2.252 .138)$, do início ao fim do curso.
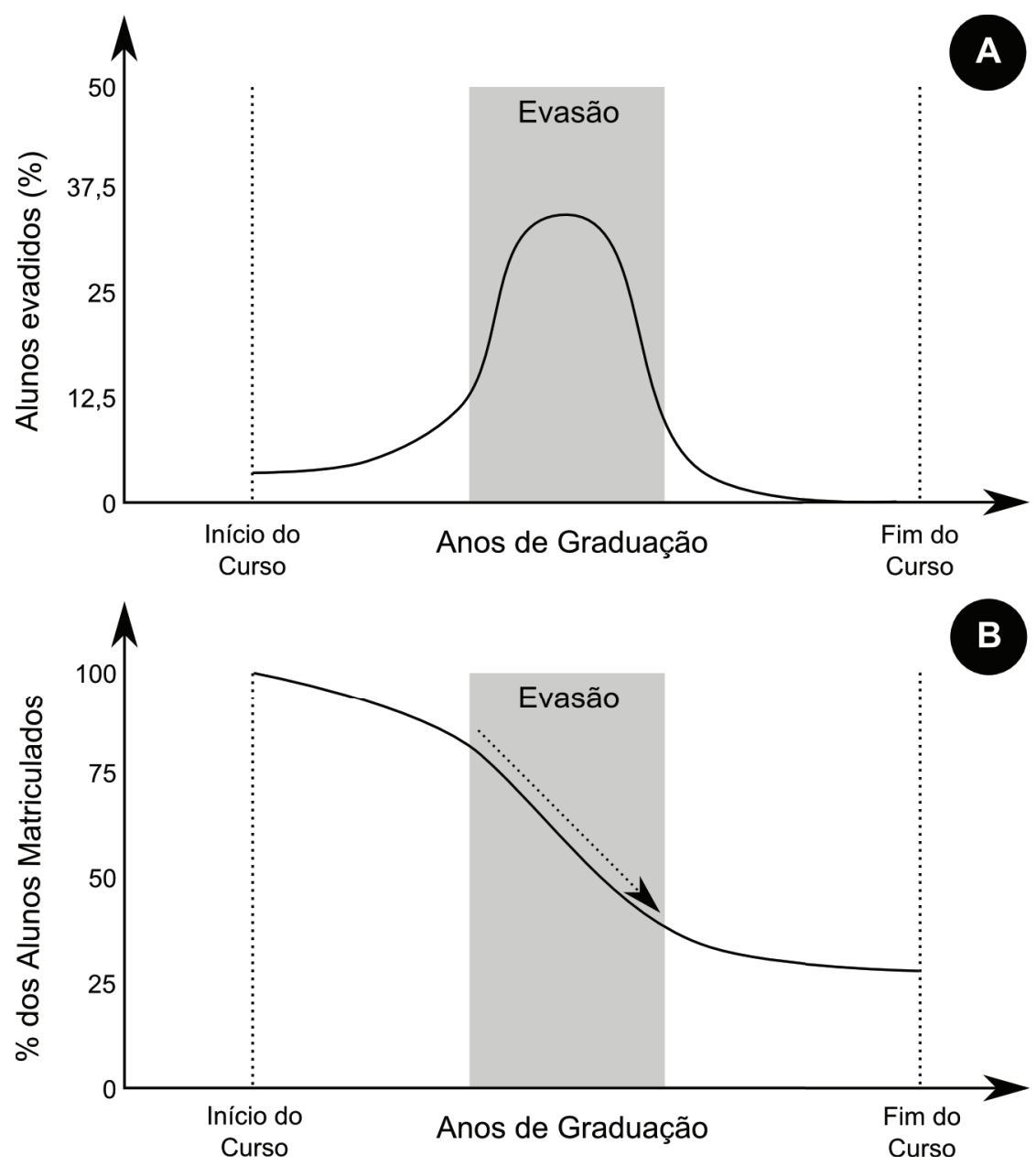

$\mathrm{O}$ que aconteceu entre o início e essa metade do curso? 23.906 responderam às perguntas abertas (Tabela 1 ). $\mathrm{Na}$ análise dos discursos através da nuvem de palavras, termos que expressam uma expectativa ou um imaginário pela profissão (CASTORIADIS, 1998) foram suscitadas (Figura 3): motivação, sonho, futuro, profissão e utopia. Outra palavra em destaque foi "sociedade" que expressa uma coletividade. Neste momento, esse sentimento de que a partir dali a potência de agir estava sustentada por uma esperança no capital acadêmico a ser adquirido, pela capacidade de transformação individual e coletiva da origem ao destino sócio-econômico-cultural, e por sua utilidade frente a sociedade (SANTANA, 2015). 
Evasão nas Licenciaturas das Universidades Federais: entre a apetência e a competência

Tabela 1 - Número de alunos entrevistados por unidade federativa do Brasil dos cursos de Licenciatura das Universidades Federais, que cursaram ou evadiram de 2007 a 2014.

\begin{tabular}{llll}
\hline Estados & Início do Curso & Evadidos & Fim do Curso \\
\hline Acre & 145 & 242 & 206 \\
Alagoas & 499 & 462 & 152 \\
Amapá & 301 & 409 & 331 \\
Amazonas & 377 & 167 & 290 \\
Bahia & 170 & 155 & 417 \\
Ceará & 276 & 341 & 348 \\
Distrito Federal & 119 & 439 & 490 \\
Espírito Santo & 207 & 260 & 182 \\
Goiás & 395 & 148 & 130 \\
Maranhão & 203 & 415 & 463 \\
Mato Grosso & 242 & 296 & 228 \\
Mato Grosso do Sul & 277 & 421 & 248 \\
Minas Gerais & 441 & 481 & 193 \\
Pará & 360 & 491 & 352 \\
Paraíba & 257 & 312 & 245 \\
Paraná & 494 & 397 & 220 \\
Pernambuco & 360 & 209 & 327 \\
Piauí & 164 & 274 & 304 \\
Rio de Janeiro & 454 & 405 & 263 \\
Rio Grande do Norte & 241 & 113 & 208 \\
Rio Grande do Sul & 339 & 253 & 424 \\
Rondônia & 318 & 398 & 158 \\
Roraima & 375 & 109 & 489 \\
Santa Catarina & 216 & 193 & 137 \\
São Paulo & 316 & 242 & 207 \\
Sergipe & 308 & 116 & 271 \\
Tocantins & 313 & 326 & 383 \\
\hline TOTAL & 8.166 & 8.075 & 7.665 \\
\hline & & & \\
\hline
\end{tabular}

Figura 3 - Nuvem de palavras mais citadas nas démarches dos discursos dos alunos ingressantes nos Cursos de Licenciatura das Universidades Federais.

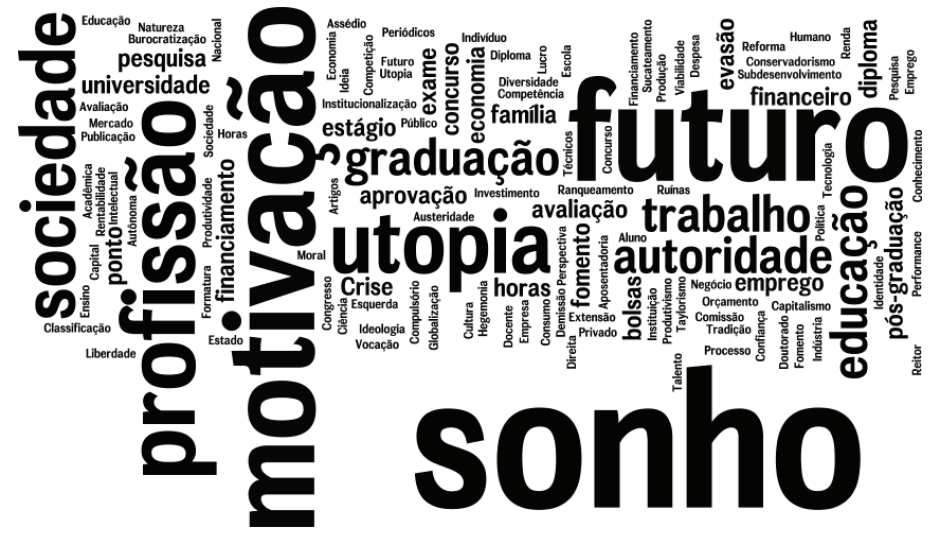

No momento da evasão existe uma perda da "essência em ato" (ESPINOZA, 2007), ou seja, há uma desmotivação no curso, há uma distopia da potência inicial vistas pelas palavras suscitadas: desmotivação, bolsas, financiamento, financeiro e trabalho (Figura 4). Parece que há um encontro prático com a realidade, na qual descende um platonismo e desfaz expectativas. Nesse momento, todos os tópicos levantados 
pela literatura e apontados anteriormente emergiram (ANDRIOLA; ANDRIOLA; MOURA, 2006; SILVA FILHO et al., 2007; BARDAGI; HUTZ, 2009; BAGGI; LOPES, 2011; TONTINI; WALTER, 2014): i) falta de uma recepção e orientação no início do curso; ii) realidade distante do imaginário pré-universitário (eg. impacto de uma educação disciplinadora no ensino médio para uma educação libertadora no ensino superior); iii) um distanciamento na relação professor-aluno; iv) não identificação com as disciplinas e expectativas não correspondidas (escolha vocacional insuficiente); v) discriminação e pouca integração social; vi) falta de perspectiva com a profissão escolhida; vii) problemas familiares (eg. distância da família, ciúmes ou conservadorismo do cônjuge, etc.); viii) problemas financeiros (eg. falta de auxílios de manutenção acadêmica); ix) baixo coeficiente de rendimento acadêmico (resultado de um ensino médio defasado); $\mathrm{x}$ ) escassez de tempo (eg. incompatibilidade com horário do trabalho).

Figura 4 - Nuvem de palavras mais citadas nas démarches dos discursos dos alunos no momento da evasão dos Cursos de Licenciatura das Universidades Federais.

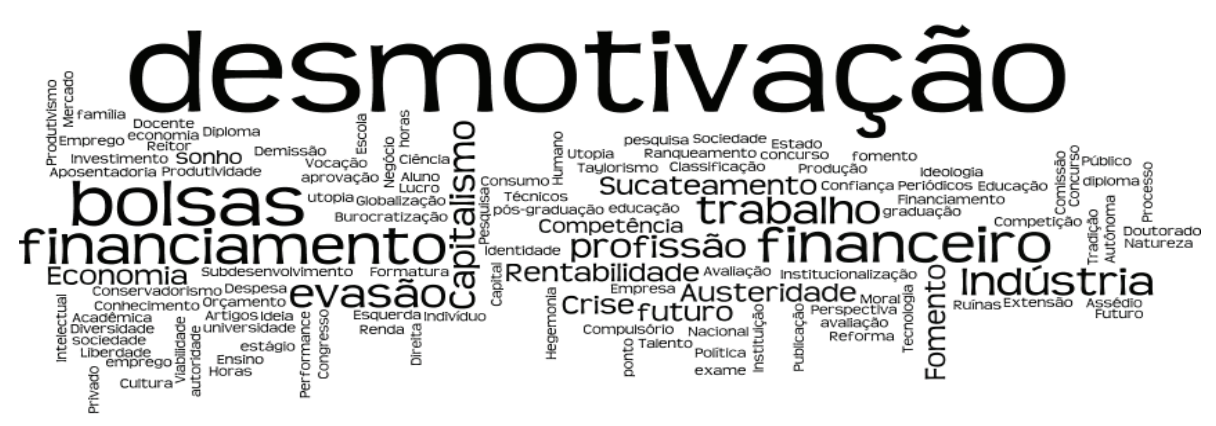

Alguns dados confirmaram o que foi descrito na literatura, como o baixo rendimento acadêmico no momento da evasão (Figura 5). O destaque foi que houve uma diferença significativa das notas em relação ao início do curso $(\mathrm{p}<0,015)$, porém não significativa em relação aos alunos que permaneceram no curso $(p>0,050)$. Isso pôde ressaltar que o coeficiente de rendimento pode ser um dos fatores, mas não o fator da evasão. E reforça aqui que a questão não está somente na investigação de quem evadiu, mas também na indagação dos que permaneceram. A observar o perfil dos alunos no momento da evasão (Figura $6 \mathrm{~A}$ ), os alunos do gênero masculino evadem mais que os alunos do gênero feminino (63\%), acentuando a conclusão dos cursos de licenciatura mais por alunos do gênero feminino, que também ingressaram mais. A discussão sobre a questão de gênero e evasão nas universidades descritas na literatura foram alocadas em um campo mais de incerteza do que em um campo de uma afirmação probabilística. Enquanto alguns autores afirmaram que os alunos do gênero masculino evadiram para entrar no mercado de trabalho (STEEG; ELK; WEBBINK, 2015), e que mulheres não estão dispostas a mudanças bruscas (sair ou mudar de um curso de graduação), dados que não se sustentam (XENOS; PIERRAKEAS; PINTELAS, 2012), mostrou que na contemporaneidade a particularidade do gênero não determinou a decisão pela evasão (MONTMARQUETTE; MAHSEREDJIAN; HOULE, 2001). 
Figura 5 - Coeficiente de Rendimento Acadêmico (CRA) dos alunos no início, no momento de maior evasão e no fim dos Cursos de Licenciatura das Universidades Federais. ns = não significativa e $p=$ resultado do teste $\mathrm{t}$.

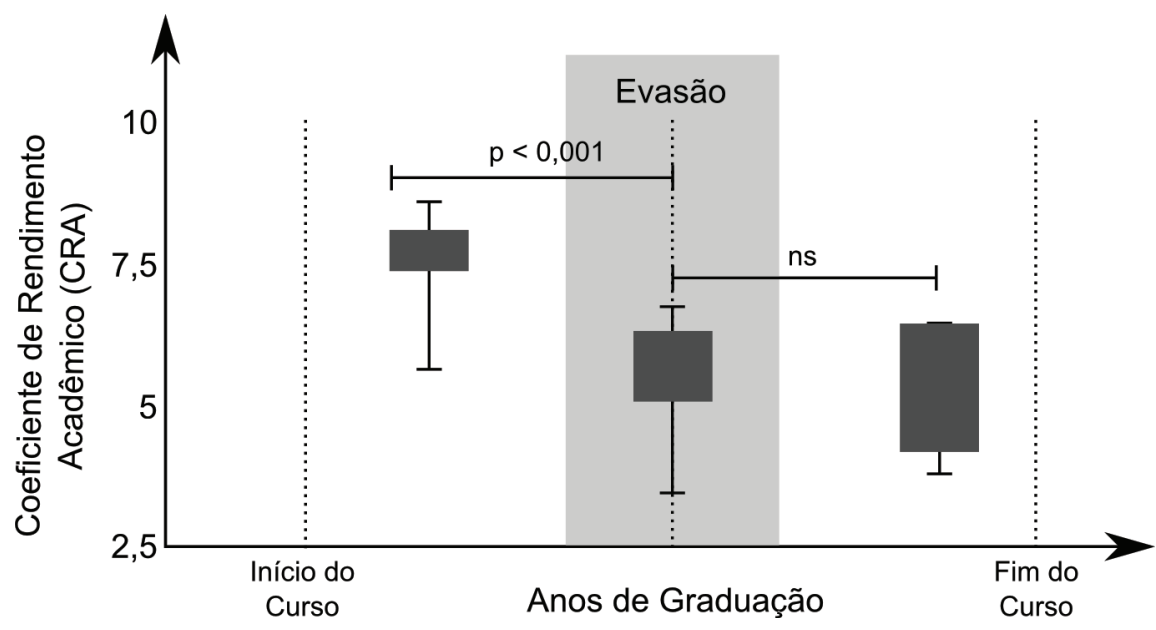

A renda familiar dos evadidos são maiores do que os do início e dos que permaneceram no curso ( $p<0,015$; Figura $6 \mathrm{~B})$, o que faz inferir que o fator financeiro foi decisivo para permanência. $46 \%$ dos evadidos residiam em ambientes familiares que recebiam de 7 a 19 salários mínimos. Os dados evidenciaram que quem foi proveniente de famílias com rendimentos inferiores a 6 salários foram mais persistentes para o final do curso, conforme observado por Montmarquette, Mahseredjian e Houle (2001). Nas metrópoles e cidades com mais de 500.000 habitantes a distância da residência do aluno até a universidade, associada as precárias condições de mobilidade e transportes públicos, representaram uma barreira e causa para desmotivação e baixo rendimento acadêmico por parte dos estudantes (SANTANA et al., 2013). A distribuição dos dados da distância da residência a universidade dos alunos que evadiram não teve diferença significativa $(p>0,050)$ dos alunos do início do curso, porém significativa em relação aos alunos no final do curso $(p<0,001)$. 74\% dos alunos que permaneceram residiam a menos de $10 \mathrm{~km}$ da universidade (Figura 6C), isto possivelmente pela necessidade de estarem mais tempo na Universidade ao final do curso, ou pelas demandas das disciplinas e estágios obrigatórios, ou engajamento em algum projeto (pesquisa, extensão ou tecnológico) (SANTANA et al., 2013). Em relação a distribuição dos dados da idade dos que evadiram (Figura 6D), não houve uma diferença significativa em relação aos alunos que permaneceram $(\mathrm{p}>0,500)$, o que evidenciou que a idade não influenciou no momento da evasão. A diferença em relação ao início do curso se deve principalmente pela ascensão da idade natalícia. 
Figura 6 - (A) Coeficiente de Rendimento Acadêmico (CRA), (B) rendimento familiar, (C) distância da residência a universidade, e (D) idade dos alunos no início, no maior momento de evasão e no fim dos Cursos de Licenciatura das Universidades Federais. ns $=$ não significativa e $\mathrm{p}=$ resultado do teste $\chi^{2}$.
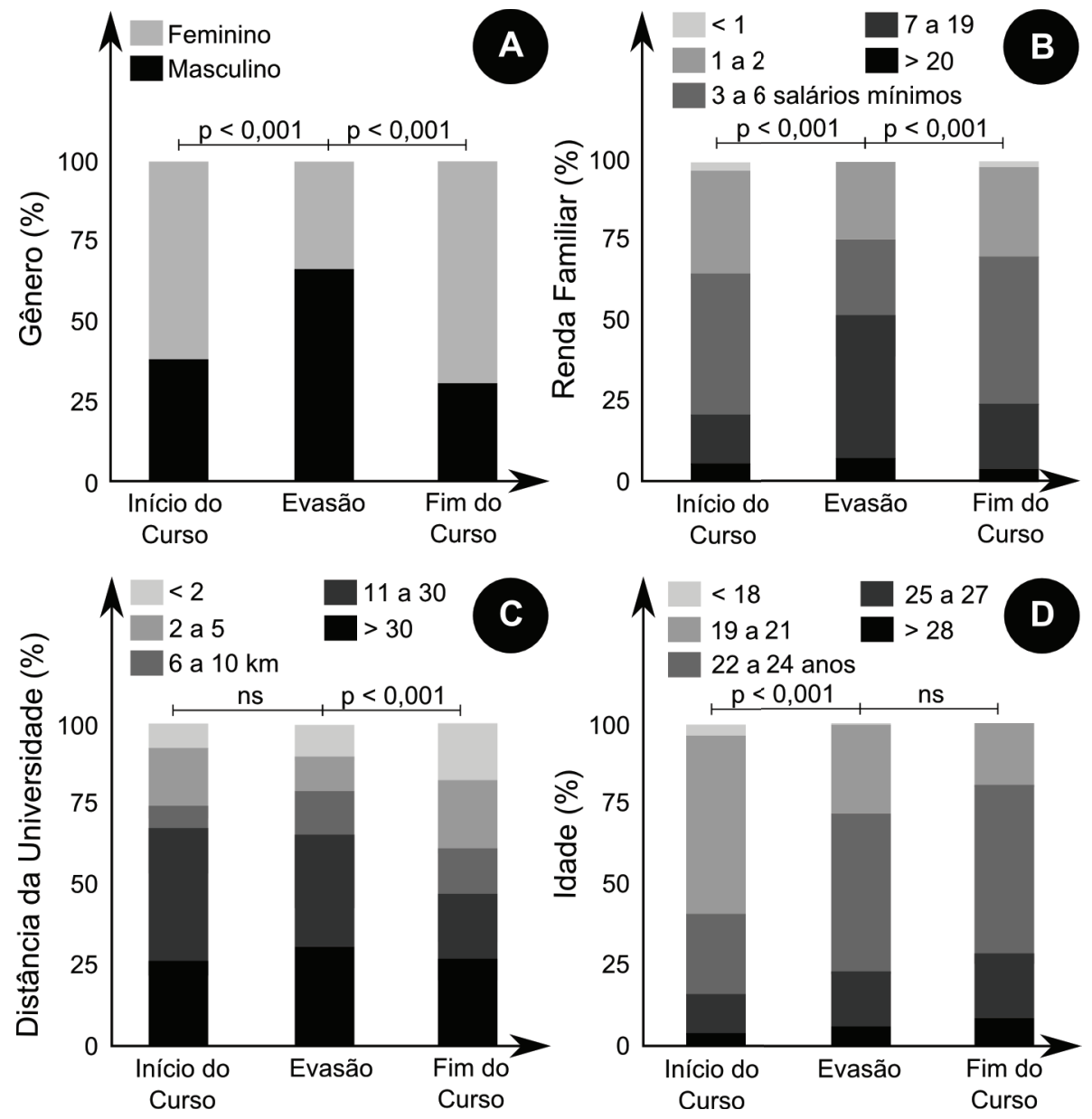

Nos discursos dos alunos que permaneceram no final do curso, suscitaram as seguintes palavras (Figura 7): profissão, currículo, mercado, bolsas e avaliação. Palavras mais concretas do que as do início do curso. Outras palavras emergidas: financeiro, empresa, competência e produtividade, refletiram o foco na busca da sustentação do capital acadêmico (diploma) por outros capitais: completar o currículo. Nesse período, a busca por participações em eventos, cursos, por produções de trabalhos científicos para eventos e periódicos, e por orientações e relações acadêmicas (eg. participação em grupos de pesquisa) demonstrou não somente uma maturidade acadêmica, mas principalmente a busca pela suplementação quantitativa do currículo, na qual Corbally e Grant (2015) descreveram como a construção da narrativa da competência (o currículo para competir). 
Figura 7 - Nuvem de palavras mais citadas nas démarches dos discursos dos alunos no final dos Cursos de Licenciatura das Universidades Federais.

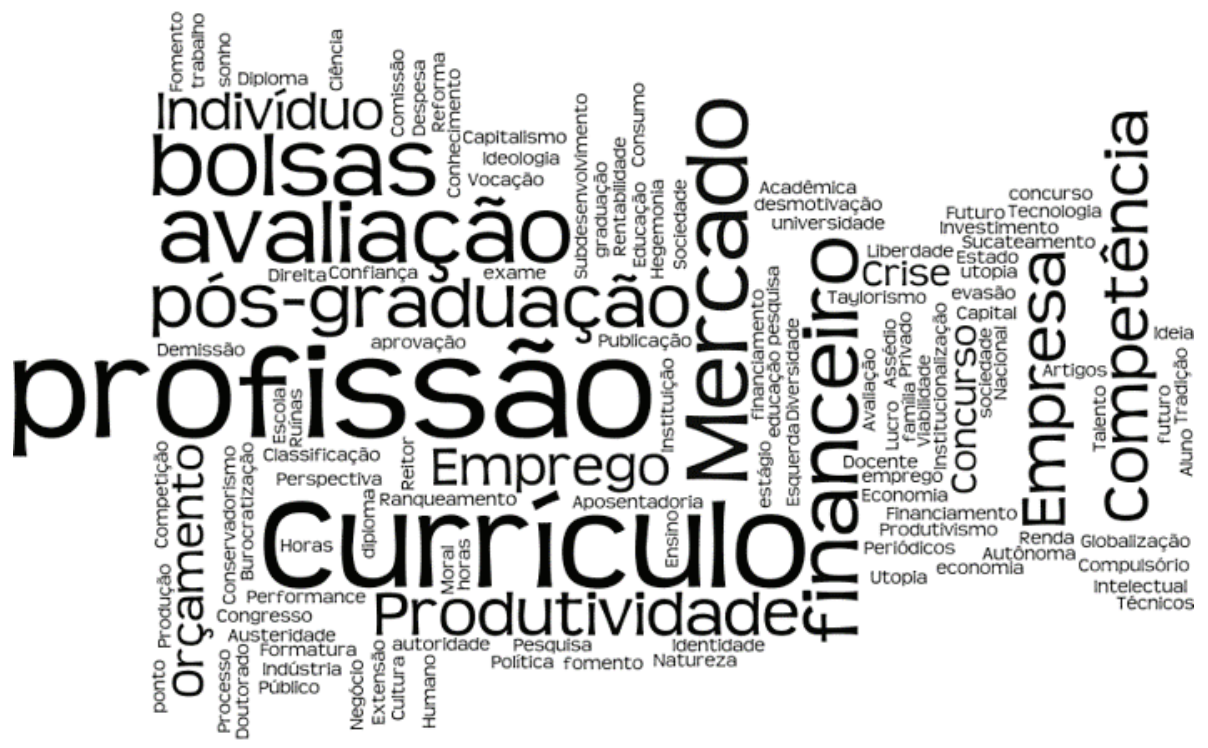

A percepção nos discursos de uma travessia (dialogicidade) de um tempo vindouro ideológico ou platônico ("avenir", ver DELEUZE; GUATTARI, 1980) para um futuro concreto, evidenciou uma potência de agir que migrou de uma apetência para competência. E no momento em que houve a perda da essência em ato pela apetência e baixa motivação pela competência, se deram os maiores números de evasão (Figura 2 e Figura 8). Existe uma potência de agir pelos alunos no início e no fim do curso, porém essas potências são distintas, não vistas em alunos na transitividade da metade do curso. As causas apresentadas pela literatura para evasão, e corroboradas com os dados desse trabalho, foram apenas fatores que ajudaram aos alunos a justificarem suas desistências e seus abandonos em um momento de perda do platônico e do não enfrentamento do real (do que o sistema requisita). Talvez aqui as semânticas das expressões de "sobrevivência" (RESTAINO, 2008) e "persistência" (LEVY, 2007) se encaixariam não pelo aluno perpassar uma causa ou um conjunto de fatores (obstáculos), mas pelo aluno perpassar um período de baixa potência de agir. Sociologicamente, essa travessia representaria a transformação dos alunos de agentes de mudanças sociais (BOURDIEU, 1983) a participantes do jogo institucional (CROZIER, 2000), em que a potência se dá pelo que as instituições (futuros empregos ou pós-graduação) solicitam como pré-requisito para sua absorção, e não por seus imaginários na atuação na profissão (início do curso). Essa possível teoria pode ser sintetizada na Figura 8. 
Figura 8 - Momento da evasão e potências de agir por apetência e por competência do início ao fim dos Cursos de Licenciatura das Universidade Federais.

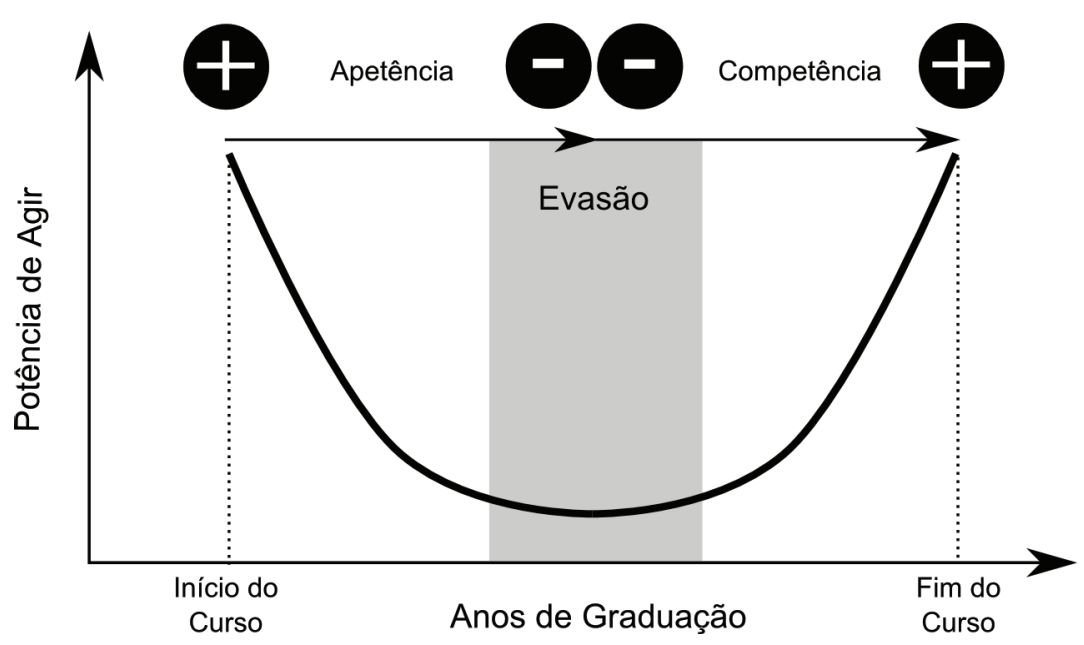

Outro destaque foi que os alunos que permaneceram até o fim dos cursos de licenciatura também concordaram, em pesos próximos (Tabela 2), terem os obstáculos correntes que os que evadiram justificaram como causa. Variação na mensuração dos pesos menores do que três (escala de 10 possíveis respostas de satisfação), significa que não há uma discordância entre dois conjuntos de observadores (LIKERT, 1932; SANTANA, 2014). Esse dado, apesar de não determinista, reforça a narrativa de que apenas uma causa ou de um conjunto de causas não determina a evasão, apoiada pelos dados quantitativos e qualitativos posteriormente apresentados.

Tabela 2 - Pesos médios avaliados pelos alunos que evadiram $(\bigcirc)$ e pelos alunos que permaneceram $(\square)$ na concordância de passarem por obstáculos correntes em cursos de licenciaturas das Universidades Federais.

Obstáculos Correntes

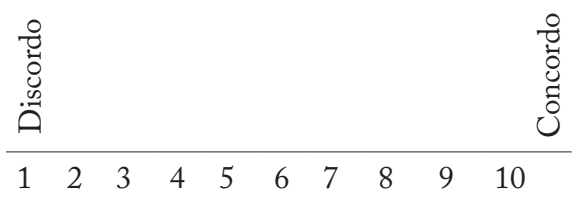

i) falta de uma recepção e orientação no início do curso

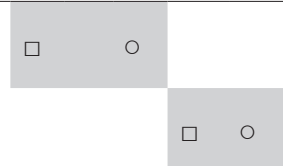

ii) realidade distante do imaginário préuniversitário

iii) um distanciamento na relação professoraluno

iv) não identificação com as disciplinas e expectativas não correspondidas

v) discriminação e pouca integração social

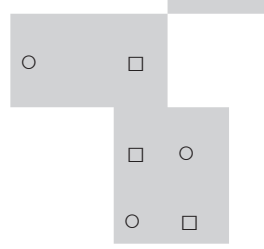


vi) falta de perspectiva com a profissão escolhida

vii) problemas familiares

viii) problemas financeiros

ix) baixo coeficiente de rendimento acadêmico

$\mathrm{x})$ escassez de tempo

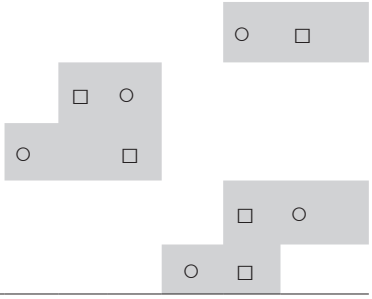

Alguns autores destacaram que o processo de evasão também possa estar correlacionado a narrativa do aluno frente ao exemplo familiar ou de seu grupo social adjacente (BOURDIEU, 2008; LIMA JUNIOR; OSTERMANN; REZENDE, 2013). A baixa escolaridade dos pais ou das pessoas próximas poderia afetar sensivelmente no sucesso e no fracasso escolar (e.g. tempo de permanência na instituição acadêmica), devido a outras atividades a serem exercidas pelos alunos concomitantemente a academia (e.g. trabalho), e a retenção por um longo período nos semestres básicos (uma base de conhecimentos insuficiente) (LIMA JUNIOR; OSTERMANN; REZENDE, 2013). Necessitaria de um diploma para realizar os que a minha volta fazem? (Sistema das relações de classe, BOURDIEU, 2008). Suscitaria aí a questão da reprodução cultural (habitus, BORDIEU, 2009) e do "exemplo" daquilo que o sujeito poderia ser instruído a imitar ou dissuadir frente as relações institucionais (mercado de trabalho) (WAGENSCHEIN, 1965). O tempo presente é uma variável importante para esse sujeito frente as instituições (ELIAS, 1990), na qual poderia emergir o seguinte dilema: permanecer na academia ou ir ao mercado de trabalho sem o diploma acadêmico, o que o levaria a um reconhecimento institucional rápido (e.g. possuir uma carteira de trabalho).

\section{Considerações finais}

Ao se retornar a hipótese inicial: existe um momento em que a potência de agir se reduziria a ponto da evasão ser a alternativa nos cursos de licenciatura das Universidades Federais, pode-se inferir que existe, e que esse momento foi principalmente a metade do curso. Essa baixa potência de agir foi devido à perda da apetência, do imaginário e do platonismo sobre o curso construído pelo aluno antes do ingresso à universidade e na qual os que persistiram resignificaram essa apetência pela busca da competência na transitividade do início ao fim do curso. Os alunos que sobreviveram passaram da abstração do curso para o concreto, nas quais as instituições pós-universidade (pós-graduação e mercado) requerem, ou seja, as causas apresentadas e citadas pela literatura foram mais justificativas pós-abandono do que fatores determinísticos para a evasão.

As universidades federais trabalham juntamente com os programas federais para a eliminação das causas da evasão, além disso, disponibilizam aos alunos editais de bolsas e auxílios manutenção (moradia e alimentação), psicólogos, auxílios a eventos, cursos extracurriculares de formação e outros. Porém, a elevada potência de agir individual, "o desejo que lhe coloca em movimento" (ESPINOZA, 2007), resultado das relações sociais (ROUSSEAU, 1962), das interações nas instituições (ambiente, objetos educacionais e atores) (VIGOTSKY, 1989), e pelo próprio indivíduo (PIA- 
GET, 1971) perpassa obstáculos. Cross (1981) e Amilburu (2011) defendem uma universidade não compulsória, uma universidade vocacional nas bases do desenvolvimento humano, educação não como meio (capital humano), mas como parte de uma educação continuada que não cessa ao longo da vida (lifelong learning). Com isso, a potência de agir vocacionalmente sempre seria alimentada por um misto de 'sonho' profissional (apetência) e concretude do sistema (competência) solicitados pela sociedade (primum principium) e pelo mercado. Com isso, se fortaleceria a figura do intelectual, que persegue a autodisciplina e autonomia (GRAMSCI, 1968), e que por suas características persistiria e sobreviveria mais a um percurso acadêmico, e consequentemente poucos evadiriam, frente a figura corrente do academicista (cumpridores de créditos curriculares) em uma educação produtora de capital humano (OURIQUES; RAMPINELLI; TAVARES, 2011), na qual um ou mais obstáculos são motivos para o abandono ou desistência. A vocação é basilar de qualquer profissão, porém, na formação de um docente, e nas suas práxis, ela sempre deverá ser revisitada pelos desafios contingentes (epistemologia) que surgem na rotina profissional do professor, além de qualquer técnica, a serem atenuados pelo sensível (poiésis), que possivelmente se encontra no imaginário e na intuição de um aluno apetente ingressante nas Licenciaturas.

\section{Agradecimentos}

Ao grupo de pesquisa "Educometria" (DBR/CB/UFPE - educometry.blogspot.com) pelo suporte na coleta e interpretação dos dados, e a Pró-Reitoria de Extensão e Cultura da Universidade Federal de Pernambuco (PROExC/UFPE) pelo apoio financeiro (Editais PIBEX/UFPE 2014 e 2015).

\section{Referências}

AMILBURU, M. G. ¿ Tiene futuro la Universidad? Análisis desde la Filosofía de la Educación. Revista Portuguesa de Pedagogía, SI, p. 57-67, 2011.

ANDRIOLA, W. B.; ANDRIOLA, C. G.; MOURA, C. P. Opinióes de docentes e de coordenadores acerca do fenômeno da evasão discente dos cursos de graduação da Universidade Federal do Ceará (UFC). Ensaio: Avaliação e Políticas Públicas em Educação, v. 14, n. 52, p. 365-382, 2006.

BAGGI, C. A. Dos S.; LOPES, D. A. Evasão e avaliação institucional no ensino superior: uma discussão bibliográfica. Avaliação, v. 16, n. 2, p. 355-374, 2011.

BARDAGI, M. P.; HUTZ, C. S. "Não havia outra saída”: percepções de alunos evadidos sobre o abandono do curso superior. Psico-USF, v. 14, n. 1, p. 95-105, 2009.

BECKER, G. S. Human capital: A theoretical and empirical analysis, with special reference to education. Chicago: University of Chicago Press, 2009.

BILLOUET, P. Débattre: Pratiques scolaires et démarches éducatives. Paris: L'Harmattan. 2007.

BOURDIEU, P. Questões de sociologia. Rio de Janeiro: Marco Zero. 1983.

. Futuro de classe e causalidade do provável. In: NOGUEIRA, M. A.; CATANI, A. Escritos de educação. Petrópolis: Vozes, 2008. p. 81-126.

Reprodução cultural e reprodução social. In: BOURDIEU, P. A economia das trocas simbólicas. 6. ed. São Paulo: Perspectiva, 2009. p. 295-336. 
CORBALLY, M.; GRANT, A. Narrative competence: A neglected area in undergraduate curricula. Nurse Education Today, v. 35, n. 12, p. 1054-1061, 2015.

CASTORIADIS, C. The imaginary institution of society. Cambridge: Mit Press, 1998.

CROSS, K. P. Adults as Learners. Increasing Participation and Facilitating Learning. San Francisco: Jossey-Bass, 1981.

CROZIER, M. A quoi sert la sociologie des organisations? Paris: Seli Arslan. 2000.

DELEUZE, G.; GUATTARI, F. Mil platôs: capitalismo e esquizofrenia. Rio de Janeiro: 34, 1980.

DINIZ-PEREIRA, J. E. A situação atual dos cursos de licenciatura no Brasil frente à hegemonia da educação mercantil e empresarial. Revista Eletrônica de Educação, v. 9, p. 273-280, 2015.

ELIAS, N. O Processo Civilizador: Uma história dos costumes. Rio de Janeiro: Jorge Zahar, 1990.

ESPINOZA, B. Ética. Belo Horizonte: Autêntica, 2007.

FELICETTI, V. L.; FOSSATTI, P. Alunos ProUni e não ProUni nos cursos de licenciatura: evasão em foco. Educar em Revista, n. 51, p. 265-282, 2014.

FREIRE, P. Educação como prática da liberdade. São Paulo: Paz e Terra, 2014. Terra, 1996

Pedagogia da autonomia: saberes necessários à prática educativa. São Paulo: Paz e

GATTI, B. A.; BARRETTO, E. S. de S.; ANDRÉ, M. E. D. A. de. Políticas Docentes no Brasil: um estado da arte. 1. ed. Brasília, DF: UNESCO, 2011. v. 1.297p.

GOMES, A. M.; MORAES, K. N. Educação superior no Brasil contemporâneo: transição para um sistema de massa. Educação \& Sociedade, v. 33, p. 171-190, 2012.

GRAU-VALLDOSERA, J.; MINGUILLÓN, J. Rethinking dropout in online higher education: The case of the Universitat Oberta de Catalunya. The International Review of Research in Open and Distributed Learning, v. 15, n. 1, p. 291-308, 2014.

GRAMSCI, A. Os intelectuais e a organização da cultura. Rio de Janeiro: Civilização Brasileira. 1968.

HEIDEGGER, M. Interprétations phénoménologiques d'Aristóteles. Paris: Trans. Europ. Repress, 1976.

KAUFMANN, J. C. L'Entretien compréhensif. Paris: Armand Colin, 2004.

LEGINUS, M.; et al. Methodologies for improved tag cloud generation with clustering. Web Engineering, v. 7387, p. 61-75, 2012.

LEVY, Y. Comparing dropouts and persistence in e-learning courses. Computers \& Education, v. 48, n. 2, p. 185-204, 2007.

LIMA JUNIOR, P.; OSTERMANN, F.; REZENDE, F. Análise dos condicionantes sociais do sucesso acadêmico em cursos de graduação em Física à luz da sociologia de Bourdieu. Ensaio: Pesquisa em Educação em Ciências (Impresso), v. 15, p. 113-129, 2013.

LIKERT, R. A technique for the measurement of attitudes. Archives of Psychology, v. 22, p. 140-155, 1932.

MEC/INEP/DEED. Ministério da Educação/Instituto Nacional de Estudos e Pesquisas Educacionais Anísio Teixeira/Departamento de Estatísticas Educacionais. Censo da Educação Superior. Disponível em: < http://portal.inep.gov.br/web/censo-da-educacao-superior >. Acesso em: Jan 2015. 
MONTMARQUETTE, C.; MAHSEREDJIAN, S.; HOULE, R. The determinants of university dropouts: a bivariate probability model with sample selection. Economics of Education Review, v. 20, n. 5, p. 475-484, 2001.

OURIQUES, N. D.; RAMPINELLI, W. J.; TAVARES, E. Crítica à razão acadêmica. Florianópolis: Insular, 2011.

PIAGET, J. A epistemologia genética. Petrópolis: Vozes, 1971.

RESTAINO, M. Dropping out of University of Salerno: a survival approach. Salerno: CUSL - Fisciano, 2008.

REUNI. Reestruturação e Expansão das Universidades Federais. Ampliação da Oferta de Educação Superior Pública. Disponível em: < http://reuni.mec.gov.br/ > . Acesso em: jan. 2015.

ROMANOWSKI, J. P. Licenciaturas no Brasil: um balanço das teses e dissertações. 1. ed. São Paulo: USP, 2002.v. 1.146p.

ROUSSEAU, J. J. Du contrat social, ou, Principes du droit politique: discours sur les sciences et les arts. Paris: Garnier Frères, 1962.

SANTANA, O. A. Teachers in Brazil: Social Mobility and Elements for Federalism Strategies. Creative Education, v. 06, p. 1629-1637, 2015.

2014.

Observação da Prática Docente: Um método para Licenciatura. Olinda: Livro Rápido,

A. Alunos egressos das licenciaturas em EAD (consórcios setentrionais e UAB: 20012012), sua empregabilidade e absorção pelo mercado. Revista Brasileira de Aprendizagem Aberta e a Distância, v. 12, p. 47-58, 2013.

. et al. Integration of face-to-face and virtual classes improves test scores in Biology undergraduate courses on days with flooding in Brazil. Acta Scientiarum. Education, v. 35, n. 1, p. 117-123, 2013.

SILVA FILHO, R. L. L. et al. A evasão no ensino superior brasileiro. Cadernos de Pesquisa, v. 37, n. 132, p. 641-659, 2007.

STEEG, M. V. D.; ELK, R. V.; WEBBINK, D. Does intensive coaching reduce school dropout? Evidence from a randomized experiment. Economics of Education Review, v. 48, p. 184$197,2015$.

SKYPE. Conectar. Disponível em: <www.skype.com>. Acesso em: jan. 2015.

TONTINI, G.; WALTER, S. A. Pode-se identificar a propensão e reduzir a evasão de alunos?: ações estratégicas e resultados táticos para instituições de ensino superior. Avaliação, v. 19, n. 1, p. 89-110, 2014.

WAGENSCHEIN, M. Exemplarisches Lehren. Frankfurt: Schroedel, 1965.

WOODLEY, A. Conceptualizing student dropout in part-time distance education: pathologizing the normal? Open Learning: The Journal of Open, Distance and e-Learning, v. 19, n. 1, 2004.

VIGOTSKY, L. S. A formação social da mente: o desenvolvimento dos processos psicológicos superiores. São Paulo: Martins Fontes, 1989.

XENOS, M.; PIERRAKEAS, C.; PINTELAS, P. A survey on student dropout rates and dropout causes concerning the students in the Course of Informatics of the Hellenic Open University. Computers \& Education, v. 39, n. 4, p. 361-377, 2002. 
* Professor doutor da Universidade Federal de Pernambuco, Recife, Pernambuco, Brasil.

\section{Correspondência}

Otacílio Antunes Santana - Universidade Federal de Pernambuco, Centro de Ciências Biológicas, Departamento de Biofísica e Radiobiologia. Av. Prof. Moraes Rego, Cidade Universitária, CEP: 50670901, Recife, Pernambuco - Brasil.

E-mail: otaciliosantana@gmail.com

Recebido em 27 de outubro de 2015

Aprovado em 15 de março de 2016 